\title{
Keanekaragaman dan kelimpahan Collembola pada perkebunan kelapa sawit di Kecamatan Bajubang, Jambi
}

\author{
Diversity and abundance of Collembola in \\ oilpalm plantation at Bajubang, Jambi
}

\author{
Joko Warino ${ }^{*}$, Rahayu Widyastuti ${ }^{1}$, Yayuk Rahayuningsih Suhardjono ${ }^{2}$, Budi Nugroho $^{1}$ \\ ${ }^{1}$ Departemen Sumber Daya Lahan, Fakultas Pertanian, Institut Pertanian Bogor \\ Jalan Meranti, Kampus IPB Dramaga, Bogor 16680 \\ ${ }^{2}$ Pusat Penelitian Biologi, Lembaga Ilmu Pengetahuan Indonesia \\ Jalan Raya Jakarta-Bogor Km. 46, Cibinong-Bogor 16911
}

(diterima Mei 2016, disetujui Juni 2017)

\begin{abstract}
ABSTRAK
Collembola adalah organisme yang bermanfaat bagi kesehatan tanah karena membantu dalam perombakan bahan organik dalam rantai makanan dan perannya masih belum dikenal secara luas di Indonesia. Informasi tentang Collembola sangat terbatas, terutama di perkebunan kelapa sawit sehingga sangat menarik untuk dikaji. Penelitian bertujuan untuk mempelajari kelimpahan dan keanekaragaman Collembola pada perkebunan kelapa sawit serta mengkaji pengaruh faktor lingkungan (curah hujan dan kelembaban) terhadap Collembola. Penelitian dilakukan di Perkebunan kelapa sawit rakyat di empat desa, yaitu Bungku, Pompa Air, Sungkai, dan Singkawang di Kecamatan Bajubang, Jambi. Pengamatan dilakukan pada bulan November 2013 hingga April 2014. Pengambilan contoh tanah dilakukan dengan menggunakan pisau berbentuk segi empat berukuran $16 \mathrm{~cm}$ x $16 \mathrm{~cm}$ yang dimasukkan ke tanah sedalam $5 \mathrm{~cm}$. Contoh tanah diambil pada empat plot yang berada pada empat desa. Pada setiap lokasi dibuat satu petak berukuran $50 \mathrm{~m}$ x $50 \mathrm{~m}$. Pengambilan contoh tanah dilakukan pada piringan dan gawangan mati, setiap bulan selama 6 bulan, sebanyak 3 sampel di piringan dan 3 sampel di gawangan mati yang dilakukan secara acak. Hasil penelitian menunjukkan bahwa Collembola yang diperoleh dari seluruh area yang diamati berjumlah 3 ordo, 7 famili, dan 21 genus dengan total kelimpahan 21.951 individu. Kelimpahan Collembola yang ditemukan pada piringan berjumlah 9.960 individu terdiri atas 3 ordo, 6 famili, dan 17 genus. Sedangkan pada gawangan mati berjumlah 11.991 individu terdiri atas 3 ordo, 7 famili, 16 genus. Di antara ketiga ordo yang ditemukan Entomobryomorpha memiliki kelimpahan tertinggi, yaitu mencapai 19.999 individu baik pada piringan maupun gawangan mati. Dari hasil penelitian diduga bahwa kelimpahan dan keanekaragaman dipengaruhi oleh pemupukan, kekeringan, dan herbisida. Pemupukan dari bahan organik dapat meningkatkan kelimpahan, sementara kekeringan dan penggunaan herbisida dapat mengurangi kelimpahan Collembola.
\end{abstract}

Kata kunci: bahan organik, curah hujan, gawangan mati, kelembaban, piringan

\begin{abstract}
Collembola are essentials for soil health, because of their are as decomposers of organic material. However, Collembola are still not widely know in Indonesia. Information about Collembola is very limited, especially in oil palm plantations, so it is very interesting to study. The research aims to study the abundance and diversity of Collembola and also examines the influence of environmental factors (rainfall and humidity) toward Collembola population. The study was conducted in smallholder oilpalm plantations in four villages namely Bungku, Pompa Air, Sungkai, and Singkawang at Bajubang
\end{abstract}

\footnotetext{
*Penulis korespondensi: Joko Warino. Departemen Sumber Daya Lahan, Fakultas Pertanian, Institut Pertanian Bogor Jalan Meranti, Kampus IPB Dramaga, Bogor 16680, Tel: 085280550113, Email: jokowarino@yahoo.com.
} 


\begin{abstract}
Jambi. The observations were conducted in November 2013 until April 2014. Soil sampling is done by using a rectangular blade measuring $16 \mathrm{~cm} \times 16 \mathrm{~cm}$ which is inserted into the ground as deep as $5 \mathrm{~cm}$. Soil samples were taken on four plots located in four villages. At each location a single plot of $50 \mathrm{~m} \times 50 \mathrm{~m}$ is made. Soil sampling was performed on the weedly zone area and inactive pathway area for 6 months, 3 samples on the open ground and 3 samples on the compost line randomly. The results showed that Collembola obtained from all observed areas were 3 orders, 7 families, and 21 genus with a total abundance of 21,951 individuals. Collembola abundance found on the weedly zone area numbered 9,960 individuals consisted of 3 orders, 6 families, and 17 genus. While at inactive pathway area numbered 11,991 individuals consisted of 3 orders, 7 families, 16 genus. Among the three orders found Entomobryomorpha has the highest abundance of 19,999 individuals, both on the weedly zone area and inactive pathway area. From the results of research suspected that high and low levels of abundance and diversity influenced by fertilization, drought, and herbicides. Fertilization of the organic matter can increase abundance, were while drought and herbicide can reduce abundance of Collembola.
\end{abstract}

Key words: compost line, moisture, open ground, organic matter, rainfall

\section{PENDAHULUAN}

Collembola merupakan organisme yang umumnya dikenal hidup di dalam tanah dan dikelompokan sebagai mesofauna karena mempunyai ukuran tubuh antara $0,25 \mathrm{~mm}$ dan $8 \mathrm{~mm}$ (Suhardjono 1992). Di dunia terdapat sekitar 6.000 spesies dari 500 genus yang telah dideskripsi (Greenslade 1991), sedangkan di Indonesia yang baru diidentifikasi sekitar 250 spesies dari 124 genus dari 17 famili (Suhardjono et al. 2012).

Peranan Collembola di dalam ekosistem tanah tidak dapat diabaikan mengingat jumlahnya yang sangat besar. Collembola berperan secara tidak langsung dalam perombakan bahan organik dan sebagai indikator perubahan keadaan tanah (Suhardjono et al. 2012). Collembola juga banyak digunakan sebagai pemantauan (monitoring) suatu ekosistem (Hopkin 1997; Saosa 2004; Migliorini et al. 2005). Collembola memberi kontribusi dalam menjaga keberlangsungan hidup predator yang menjadi musuh alami berbagai jenis hama. Peran ini sangat penting terutama pada saat kepadatan kelimpahan serangga hama rendah, misalnya pada masa setelah panen atau masa bera (Ponge et al. 2003; Kanal 2004).

Penelitian mengenai Collembola dan peranannya belum banyak dilakukan di Indonesia. Faktor yang menyebabkan kurangnya minat peneliti adalah kurang populernya Collembola. Hal ini diakibatkan karena ukuran tubuh yang kecil, habitat berada di dalam tanah, dan peranan yang tidak langsung dirasakan manusia. Akibatnya, Collembola menjadi kurang dikenal keanekaragaman, habitat, daerah sebaran, dan sifat biologinya (Suhardjono 2006).

Keberadaan Collembola dalam tanah sangat bergantung pada ketersediaan energi dan sumber makanan untuk melangsungkan hidupnya, seperti bahan organik dan biomassa yang semuanya berkaitan dengan aliran siklus karbon dalam tanah (Folser 2002). Collembola juga dipengaruhi oleh faktor-faktor lingkungan, seperti cuaca, tanah, dan vegetasi yang hidup di atasnya (Suhardjono et al. 2012).

Tingkat curah hujan dan kelembaban sangat mempengaruhi komposisi kelimpahan dan keanekaragaman Collembolla di dalam tanah (Ananthakrisnan 1978). Hal ini berakibat kelimpahan dan keanekaragaman dapat berubah-ubah dari tahun ke tahun (Russel \& Hauth 2004). Oleh karena itu, Collembola dimungkinkan menjadi indikator hayati dalam tanah (Ananthakrisnan 1978; Choudhuri \& Roy 1972; Takeda 1981).

Perkebunan kelapa sawit milik rakyat merupakan salah satu ekosistem yang menarik untuk meneliti Colembola karena proses pengolahan lahan yang dilakukan secara tradisional. Jambi merupakan daerah yang memiliki perkebunan rakyat yang luas dan dalam pengolahaannya tidak sesuai dengan pedoman budi daya sehingga menciptakan ekosistem yang unik bagi Collembola, seperti kondisi tanah yang beragam baik dari tingkat lapisan maupun kandungan bahan organik. Keunikan ekosistem tersebut mendorong penelitian ini dilakukan untuk mempelajari kelimpahan dan keanekaragaman Collembola di Perkebunan Kelapa Sawit, Kecamatan Bajubang, 
Jambi. Penelitian ini bertujuan untuk mengetahui keanekaragaman dan kelimpahan Collembola pada dua macam habitat piringan dan gawangan mati serta mengkaji pengaruh faktor lingkungan (curah hujan dan kelembaban) terhadap Collembola. Piringan merupakan daerah di sekitar pohon kelapa sawit berbentuk lingkaran dengan diameter $\pm 2 \mathrm{~m}$ yang digunakan sebagai tempat perawatan tanaman, seperti untuk lokasi pemupukan, sedangkan gawangan mati, yaitu jalur yang digunakan untuk tumpukan pelepah tua yang dipangkas

\section{BAHAN DAN METODE}

\section{Lokasi penelitian}

Penelitian dilaksanakan pada bulan November 2013-April 2014 di Perkebunan kelapa sawit rakyat yang berada di empat desa, yaitu Bungku, Pompa Air, Sungkai, dan Singkawang di Kecamatan Bajubang, Kabupaten Batanghari, Provinsi Jambi. Setiap desa diambil satu lokasi yang jauh dari perumahan.

\section{Pengambilan contoh tanah}

Pengambilan contoh tanah dilakukan dengan menggunakan pisau berbentuk segi empat berukuran sisi $16 \mathrm{~cm} \times 16 \mathrm{~cm}$ yang dimasukkan ke tanah sedalam $5 \mathrm{~cm}$. Contoh tanah diambil pada empat plot yang berada pada empat desa. Pada setiap lokasi dibuat satu petak berukuran $50 \mathrm{~m}$ x $50 \mathrm{~m}$. Pengambilan contoh tanah dilakukan pada piringan dan gawangan mati yang diambil setiap bulan selama 6 bulan, 3 sampel di piringan dan 3 sampel di gawangan mati yang dilakukan secara acak. Piringan merupakan daerah di sekitar pohon kelapa sawit berbentuk lingkaran dengan diameter $\pm 2 \mathrm{~m}$ yang digunakan sebagai tempat perawatan tanaman, seperti untuk lokasi pemupukan, sedangkan gawangan mati, yaitu jalur yang digunakan untuk tumpukan pelepah tua yang dipangkas. Proses pemisahan Collombola dari tanah dilakukan dengan menggunakan alat Kempson Extractor selama 7 hari dengan suhu $\leq 45^{\circ} \mathrm{C}$.

\section{Analisis data}

Identifikasi Collembola dilakukan sampai taraf genus mengikuti klasifikasi Suhardjono et al. (2012), sedangkan penentuan nilai kelimpahan digunakan rumus Meyer (1996). Nilai keanekaragaman takson dihitung dengan menggunakan indeks keanekaragaman (H) Shannon-Wiener (Magurran 2004). Faktor-faktor pendukung yang diamati adalah curah hujan (klimatologi muara mulian), kelembaban tanah (gravimetri), $\mathrm{C}$ total (CNS Analyzer) dan N total (CNS Analyzer).

\section{HASIL}

\section{Keanekaragaman Collembola}

Indeks keanekaragaman Collembola pada bulan November 2013, Desember 2013, dan Januari 2014 tergolong sedang, sedangkan pada bulan Februari, Maret, dan April 2014 rendah baik pada piringan maupun gawangan mati (Tabel 1). Namun, secara umum nilai indeks keanekaragaman pada gawangan mati jauh lebih tinggi dibandingkan dengan piringan, kecuali bulan Februari 2014.

\section{Kelimpahan Collembola}

Collembola yang diperoleh dari seluruh area yang diamati berjumlah 3 ordo, 7 famili, dan 21 genus dengan total kelimpahan 21.951 individu. Kelimpahan Collembola yang ditemukan pada piringan berjumlah 9.960 individu terdiri atas 3 ordo, 6 famili, dan 17 genus, sedangkan pada gawangan mati berjumlah 11.991 individu yang dapat dibedakan menjadi 3 ordo, 7 famili, 16 genus (Tabel 2). Di antara ketiga ordo yang ditemukan, Entomobryomorpha memiliki kelimpahan tertinggi, yaitu mencapai 19.999 individu, baik pada piringan ( 9.101 individu) maupun gawangan mati (10.898 indvidu).

Kelimpahan Collembola lebih banyak dijumpai di gawangan mati daripada di piringan, kecuali pada bulan Februari 2014 (Gambar 1). Hal ini disebabkan karena ada 9 genus, yaitu

Tabel 1. Keanekaragaman genus Collembola berdasarkan indeks keanekaragaman Shannon's

\begin{tabular}{lcc}
\hline Waktu & Piringan & Gawangan mati \\
\hline November 2013 & 1,53 & 1,76 \\
Desember 2013 & 1,50 & 1,56 \\
Januari 2014 & 1,58 & 1,86 \\
Februari 2014 & 1,15 & 1,00 \\
Maret 2014 & 1,16 & 1,24 \\
April 2014 & 1,20 & 1,30
\end{tabular}


Hyposgastura, Ceocobrya, Pseudosinella, Isotomiela, Pseudisotoma, Archisotoma, Folsomina, Prosoitoma, dan Folsomia (Gambar 2) yang memiliki kelimpahan yang tinggi pada piringan (Tabel 2). Kelimpahan Collembola tertinggi terdapat pada bulan Januari (769 individu $/ \mathrm{m}^{2}$ ), sedangkan kelimpahan Collembola terendah pada bulan Februari (83 individu/m²) (Gambar 1).

\section{PEMBAHASAN}

Tingginya kelompok Entomobryomorpha disebabkan oleh tingginya kelimpahan beberapa genus (Folsomides, Ceocobrya, Ascocyrtus, Heterumurus). Keempat genus tersebut merupakan Collembola yang aktif di permukaan tanah dan menempati serasah tebal (Suhardjono et al. 2012).

Dalam penelitian yang dilakukan didapatkan perbedaan kelimpahan dan keanekaragaman pada piringan dan gawangan mati. Fatimah et al. (2012) juga menemukan adanya perbedaan keanekaragaman spesies dengan jumlah individu yang melimpah pada setiap habitat, seperti permukaan, serasah, dan tanah. Sangat dimungkinkan hal ini disebabkan oleh perbedaan kondisi lingkungan yang ada.

Tingginya jumlah genus pada piringan pada bulan Februari 2014 dikarenakan terdapat vegetasi rumput-rumputan agak lembab yang diduga membuat ekosistem baik untuk kesembilan genus tersebut. Genus-genus tersebut merupakan kelompok penghuni tanah yang sebenarnya (Suhardjono et al. 2012).

Tingginya kelimpahan Collembola pada bulan Januari 2014 mungkin disebabkan karena dilakukan proses pemupukan pupuk kandang pada tanaman kelapa sawit dua minggu sebelum pengambilan contoh tanah. Dua minggu pasca dilakukan pemupukan, pupuk kandang sudah tampak seperti

Tabel 2. Keanekaragaman dan kelimpahan Collembola tanah pada area penelitian

\begin{tabular}{|c|c|c|c|c|c|}
\hline Ordo & Famili & Genus & Piringan & Gawangan mati & Jumlah \\
\hline \multirow[t]{4}{*}{ Phodomorpha } & Neanuridae & Oudemasia & 13 & 169 & 182 \\
\hline & & Friesea & 0 & 26 & 26 \\
\hline & & Cephalochorutes & 0 & 13 & 13 \\
\hline & Hypogastruridae & Hyposgatrura & 26 & 0 & 26 \\
\hline Jumlah & & & 39 & 208 & 247 \\
\hline \multirow[t]{16}{*}{ Entomobryomorpha } & Entomobryidae & Ascocyrtus & 690 & 1.589 & 2.279 \\
\hline & & Heterumurus & 1.497 & 2.383 & 3.880 \\
\hline & & Ceocobrya & 2.240 & 1.940 & 4.180 \\
\hline & & Homidia & 13 & 39 & 52 \\
\hline & & Rambutsinella & 52 & 286 & 338 \\
\hline & & Pseudosinella & 104 & 65 & 169 \\
\hline & Isotomidae & Folsomides & 4.128 & 4.440 & 8.568 \\
\hline & & Isotomiela & 65 & 39 & 104 \\
\hline & & Pseudisotoma & 65 & 26 & 91 \\
\hline & & Archisotoma & 104 & 0 & 104 \\
\hline & & Folsomina & 13 & 0 & 13 \\
\hline & & Proisotoma & 13 & 0 & 13 \\
\hline & & Subisotoma & 0 & 13 & 13 \\
\hline & & Folsomia & 104 & 0 & 104 \\
\hline & Cyphoderidae & Cyphoderopsis & 13 & 65 & 78 \\
\hline & Oncopoduridae & Harlomillsia & 0 & 13 & 13 \\
\hline Jumlah & & & 9.101 & 10.898 & 19.999 \\
\hline Symphypleona & Dicyrtomidae & Papirioides & 820 & 885 & 1.705 \\
\hline Jumlah & & & 820 & 885 & 1.705 \\
\hline Total kelimpahan & & & 9.960 & 11.991 & 21.951 \\
\hline Indeks keanekaragan & n Shannon's & & 2 & 3 & \\
\hline
\end{tabular}




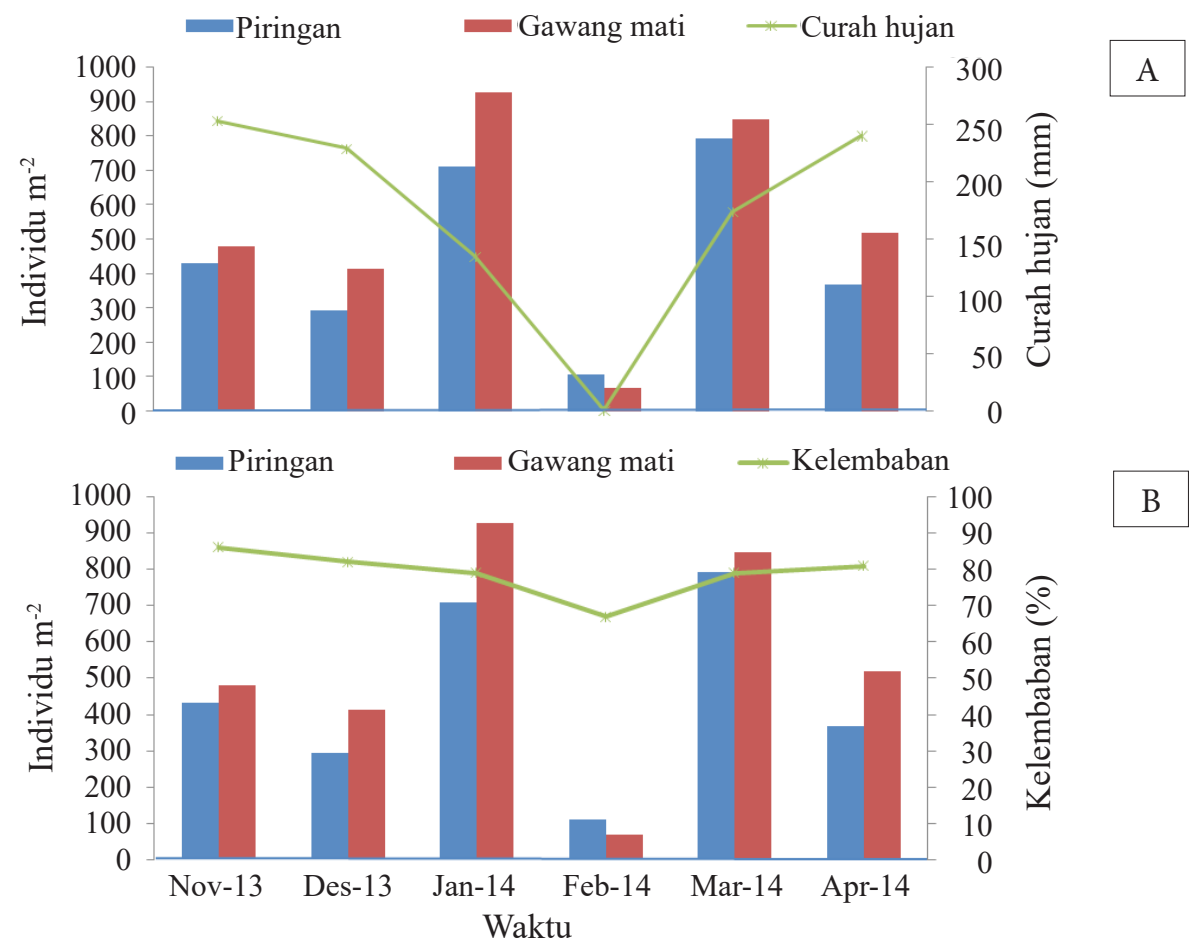

Gambar 1. Dinamika kelimpahan Collembola di piringan dan gawangan mati berdasarkan data curah hujan (A) dan kelembaban (B).

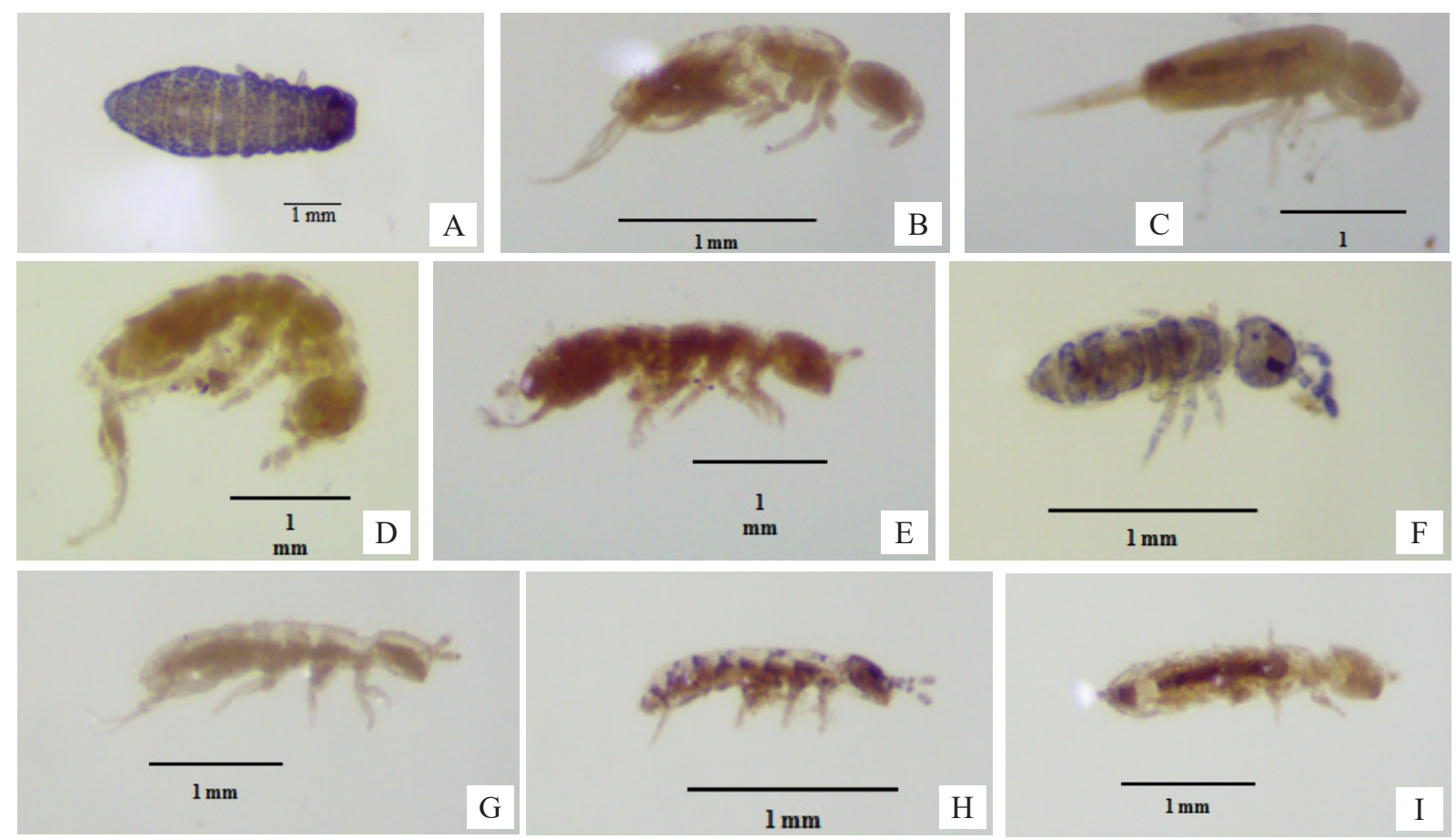

Gambar 2. Genus-genus dengan populasi tertinggi di piringan. A: Hyposgastura; B: Ceocobrya; C: Pseudosinella; D: Isotomiela; E: Pseudisotoma; F: Archisotoma; G: Folsomina; H: Prosoitoma; I: Folsomia.

terombak. Hal ini dibuktikan pada bulan Januari 2014 dimana rasio $\mathrm{C} / \mathrm{N}$ lebih tinggi dari pada bulan lainnya (November 2013 (9,79\%), Desember 2013 (11,73\%), Januari 2014 (13,25\%), Februari 2014 (8,24\%), Maret 2014 (10,39\%), April 14 $(8,86 \%))$. Pemupukan dapat meningkatkan rasio
$\mathrm{C} / \mathrm{N}$ yang berperan penting dalam pemeliharaan struktur tanah (Tian et al. 1997). Penggunaan pupuk organik secara terus-menerus dalam rentan waktu yang lama akan menjadikan kualitas tanah lebih baik sehingga daya hidup fauna tanah salah satunya Collembola akan jauh lebih tinggi. 
Kelimpahan Collembola menurun tajam pada bulan Februari 2014 ketika curah hujan $<100 \mathrm{~mm}$. Curah hujan dapat berpengaruh tidak langsung terhadap kehidupan Collembola. Tingkat kematian akan lebih tinggi pada musim kering karena Collembola tidak tahan terhadap kekeringan (Suhardjono et al. 2012). Collembola peka terhadap perubahan kelembaban tanah baik yang terjadi di atas permukaan maupun di dalam tanah. Kelembaban tanah juga mengindikasikan kandungan air tanah yang berada di sekitar tempat hidup Collembola. Christiansen (1990) menyatakan bahwa kelembaban mempunyai peran penting dalam menentukan pola distribusi Collembola. Hal tersebut serupa dengan pernyataan Suhardjono et al. (2012), kelembaban tanah memainkan peran utama dalam persebaran Collembola.

Faktor lain yang menyebabkan penurunan kelimpahan pada bulan Februari adalah adanya penyemprotan herbisida menggunakan bahan aktif Ipa Glifosat dua minggu sebelum pengamatan. Senyawa kimia tersebut dapat mempengaruhi kelimpahan Collembola yang berada di permukaan tanah dan serasah. Menurut penelitian Edward et al. (1967), pestisida organofosfat dan karbamat, seperti paration, sevin, glifosat, dan diazinon dapat menurunkan populasi fauna tanah.

Pada bulan Maret kelimpahan Collembola mengalami kenaikan kembali. Besar kemungkinan pengaruh herbisida yang diberikan pada bulan Februari telah jauh berkurang dari permukaan tanah dan curah hujan juga meningkat. Beberapa genus Collembola yang mudah mengalami pemulihan pada saat lingkungan kembali normal dari bulan Februari ke Maret adalah Folsomides dan Ascocyrtus. Hal ini disebabkan genus-genus tersebut merupakan genus yang memiliki sifat penyebaran kosmopolitan yang peka terhadap perubahan kelembaban tanah (Suhardjono et al. 2012). Curah hujan bulan April meningkat, tetapi justru kelimpahan Collembola menurun dibandingkan dengan bulan Maret. Tidak menutup kemungkinan bulan Maret merupakan bulan yang memiliki curah hujan yang optimum, sedangkan April sudah terlalu banyak air.

Nilai indeks keanekaragaman gawangan mati jauh lebih tinggi dibandingkan dengan piringan, hal ini disebabkan tingginya kelimpahan individu yang aktif pada permukaan tanah di serasah tebal di habitat gawangan mati. Hal ini juga diperkuat dengan data analisis kimia tanah yang dilakukan bahwa gawangan mati nilai $\mathrm{C}$ organik jauh lebih tinggi dibandingkan dengan piringan (Tabel 3). Hal yang sama juga terjadi pada penelitian Jumar (2000) bahwa Collembola mudah dijumpai pada bahan organik yang membusuk.

\section{KESIMPULAN}

Kelimpahan di seluruh area yang diamati adalah 21.951 individu yang terdiri atas 3 ordo, 7 famili, dan 21 genus. Terdapat perbedaan kelimpahan antara piringan (9.960 individu) dan gawangan mati (11.991 individu), begitu juga keanekaragaman genus terdapat perbedaan dan Pemupukan bahan organik dapat meningkatkan, sedangkan kekeringan dan penyemprotan herbisida menurunkan kelimpahan Collembola.

Tabel 3. Data analisis kimia tanah

\begin{tabular}{|c|c|c|c|c|}
\hline Waktu & Habitat & $\mathrm{C}(\%)$ Organik total & $\mathrm{N}$ total $(\%)$ & $\mathrm{C} / \mathrm{N}(\%)$ \\
\hline \multirow[t]{2}{*}{ November 2013} & Piringan & 1,12 & 0,15 & 7,47 \\
\hline & Gawangan mati & 2,18 & 0,18 & 12,11 \\
\hline \multirow[t]{2}{*}{ Desember 2013} & Piringan & 1,26 & 0,17 & 7,41 \\
\hline & Gawangan mati & 3,37 & 0,21 & 16,04 \\
\hline \multirow[t]{2}{*}{ Januari 2014} & Piringan & 2,09 & 0,19 & 11 \\
\hline & Gawangan mati & 3,41 & 0,22 & 15,5 \\
\hline \multirow[t]{2}{*}{ Februari 2014} & Piringan & 1,23 & 0,2 & 6,15 \\
\hline & Gawangan mati & 2,17 & 0,21 & 10,33 \\
\hline \multirow[t]{2}{*}{ Maret 2013} & Piringan & 1,55 & 0,19 & 8,16 \\
\hline & Gawangan mati & 2,65 & 0,21 & 12,62 \\
\hline \multirow[t]{2}{*}{ April 2014} & Piringan & 1,42 & 0,22 & 6,45 \\
\hline & Gawangan mati & 2,59 & 0,23 & 11,26 \\
\hline
\end{tabular}




\section{UCAPAN TERIMA KASIH}

Terima kasih penulis ucapkan kepada Collaborative Research Centre Efforts bagian B08 yang telah membantu dalam pendanaan. Kepada Departemen Ilmu Tanah dan Sumberdaya Lahan, Fakultas Pertanian, Institut Pertanian Bogor dan Universitas Jambi atas bantuan penyediaan alat baik di lapangan maupun di laboratorium. Tidak lupa terima kasih dan apresiasi kepada Laboratorium Entomologi, Bidang Zoologi atas bantuan dalam verifikasi hasil identifikasi Collembola.

\section{DAFTAR PUSTAKA}

Ananthakrisnan TN. 1978. Microarthopods and soil ecosystems. Journal of the Bombay Natural History Society 75:625-631.

Christiansen KA. 1990. Insecta: Collembola. In: Dindal DL (Ed.), Soil Biology Guide. pp. 965995. New York: John Willey and Sons.

Choudhuri DK, Roy S. 1972. An ecological study on Collembola of West Bengal (India). Records of the Zoological Survey of India 66:81-101.

Edward CA, Thompson, Beynon KL. 1967. Some effect of Chlorvinphos and Organophosphorus insectiside on population of soil animals. RavEcologycal. Biology 5:199-224.

Fatimah, Endang C, Suhardjono YR. 2012. Collembola permukaan tanah kebun karet, Lampung. Zoo Indonesia 21:17-22.

Folser J. 2002. The role of Collembola in carbon and nitrogen cycling in soil. Pedobiologia 46:234 245. doi: https://doi.org/10.1078/0031-4056-00130.

Greenslade PJ. 1991. Collembola. In: Naumann ID (Ed.), The Insect of Australia. pp. 252-264. Carlton: Melbourne University Press.

Hopkin SP. 1997. Biology of the Springtails (Insecta: Collembola). Oxford: Oxford Univ Press.

Jumar. 2000. Entomologi Pertanian. Jakarta: Rineka Cipta.

Kanal A. 2004. Effects of fertilisation and edhapic properties on soil-assosiated Collembola in crop rotation. Agronomy Research 2:153-168.
Magurran AE. 2004. Measuring Biological Diversity. Maiden: Blackwell Scientific.

Meyer E. 1996. Mesofauna. In: Schinner E, Ohlinger R, Kandeler E, Margesin R, (Eds.), Methods in Soil Biology. pp. 344. Berlin: Springer-Verla. doi: https://doi.org/10.1007/978-3-642-60966-4_23.

Migliorini M, Pigino G, Caruso T, Fanciulli PP, Leonzio C, Bernini F. 2005. Soil communities (Acari Oribatida; Hexapoda Collembola) in a clay pigeon shooting range. Pedobiologia 49:1-13. doi: https://doi.org/10.1016/j.pedobi.2004.06.009.

Ponge JF, Gillet, Dubs F, Fedoroff E, Haese L, Sousa JP, Lavelle P. 2003. Collembola communities as bioidicators of landuse intensification. Soil Biology and Biochemistry 35:813-826. doi: https://doi.org/10.1016/S0038-0717(03)00108-1.

Russel DJ, Hauth F. 2004. Community dynamics of soil Collembola in flood plains of the upper Rhine Valley. Pedobiologia 8:529-536.

Saosa JP. 2004. Effect of land-use on Collembola diversity patterns in a Mediterranean landscape. Pedobiologia 48:609-622. doi: https://doi. org/10.1016/j.pedobi.2004.06.004.

Suhardjono YR. 1992. Fauna Collembola Tanah di Pulau Bali dan Pulau Lombok. Disertasi. Jakarta: Universitas Indonesia.

Suhardjono YR. 2006. Status taksonomi fauna di Indonesia dengan tinjauan khusus pada Collembola. Zoo Indonesia 15:67-86.

Suhardjono YR, Deharveng L, Bedos A. 2012. Biologi Ekologi Klasifikasi Collembola (Ekor Pegas). Bogor: Vegamedia.

Takeda H. 1981. Efeect of shifting cultivation on the soil mesofauna with special reference to Collembola population in the North East Thailand. Memoirs of the College of Agriculture, Kyoto University 118:45-60.

Tian G, Brussard L, Kang BT, Swift MJ. 1997. Soil fauna-mediated decomposition of plant residues under contreined environmental and residue quality condition. In: Cadisch G, Giller KE (Eds.), Biological Sciences. pp. 125-134. London: Driven by Nature Plant Litter Quality and Decomposition, Department of 30, Wey College, University of London. 